\title{
Chronological and replicative life-span extension in Saccharomyces cerevisiae by increased dosage of alcohol dehydrogenase 1
}

Correspondence

Joaquim Ros

joaquim.ros@cmb.udl.es

Received 28 April 2007

Revised 3 July 2007

Accepted 10 July 2007

\author{
Gemma Reverter-Branchat, Elisa Cabiscol, Jordi Tamarit, M. Alba Sorolla, \\ M. Ángeles de la Torre and Joaquim Ros
}

\begin{abstract}
Bioquímica de l'Estrès Oxidatiu, Departament de Ciències Mèdiques Bàsiques, IRBLleida, Universitat de Lleida, 25008 Lleida, Spain
\end{abstract}

\begin{abstract}
Alcohol dehydrogenase 1 (Adh1)p catalyses the conversion of acetaldehyde to ethanol, regenerating $\mathrm{NAD}^{+}$. In Saccharomyces cerevisiae, Adh $1 \mathrm{p}$ is oxidatively modified during ageing and, consequently, its activity becomes reduced. To analyse whether maintaining this activity is advantageous for the cell, a yeast strain with an extra copy of the $A D H 1$ gene $(2 \times A D H 1)$ was constructed, and the effects on chronological and replicative ageing were analysed. The strain showed increased survival in stationary phase (chronological ageing) due to induction of antioxidant enzymes such as catalase and superoxide dismutases. In addition, $2 \times A D H 1$ cells displayed an increased activity of silent information regulator 2 (Sir2)p, an NAD ${ }^{+}$-dependent histone deacetylase, due to a higher $\mathrm{NAD}^{+} / \mathrm{NADH}$ ratio. As a consequence, a $30 \%$ extension in replicative life span was observed. Taken together, these results suggest that the maintenance of enzymes that participate in $\mathrm{NAD}^{+} / \mathrm{NADH}$ balancing is important to chronological and replicative life-span parameters.
\end{abstract}

\section{INTRODUCTION}

One of the features of ageing in Saccharomyces cerevisiae, as well as in other organisms, is the oxidative modification of specific protein targets, whose functions are impaired by such modification. A mild oxidation contributes to marking the protein for degradation (Stadtman \& Oliver, 1991), while strong oxidation can promote protein aggregation, making proteins unavailable for proteasome degradation (Grune et al., 2004). The accumulation of these modified proteins in a cell contributes to the ageing phenotype (Harman, 1981; Stadtman, 1992; Stadtman \& Levine, 2000; Levine, 2002; Nyström, 2005). In yeasts, replicative ageing refers to the number of cell divisions occurring in a mother yeast cell (Sinclair, 2002). Chronological ageing refers to the ability of cells to maintain viability in stationary phase (Herman, 2002).

During the last decade investigations of ageing have uncovered physiological and molecular mechanisms involved in this process, as well as providing some clues towards understanding life-span lengthening (Bordone \& Guarente, 2005). Calorie restriction is one of the mechanisms that has been consistently proven to extend life span in organisms ranging from yeasts to mammals (Sohal \&

Abbreviations: Adh1, alcohol dehydrogenase 1; FOXO, forkhead transcription factor; DHE, dihydroethidium; NAM, nicotinamide; ROS, reactive oxygen species; Sir2, silent information regulator 2; Sod, superoxide dismutase; WT, wild-type.
Weindruch, 1996). In yeast, the replicative life span can be increased by shifting the cells from 2 to $0.5 \%$ glucose (calorie restriction) (Lin et al., 2002, 2004). One of the key molecules is the silent information regulator 2 (Sir2)p, a class III $\mathrm{NAD}^{+}$-dependent histone deacetylase, which is involved in several physiologically important functions such as silencing telomeres and rDNA, maintaining genome integrity, and ageing (Bitterman et al., 2003). Strains that have an extra copy of the SIR2 gene have a life span extended by $40 \%$, while deletion of SIR2 shortens life span by $50 \%$ (Kaeberlein et al., 1999). Under calorie restriction, the oxygen consumption increases, thus raising the $\mathrm{NAD}^{+} / \mathrm{NADH}$ ratio by lowering the concentration of NADH. Since NADH has been described as a Sir2p inhibitor, calorie restriction results in higher Sir2p activity (Lin et al., 2002; Lin \& Guarente, 2003), contributing to life-span extension. Nevertheless, the importance of this ratio to the activation of Sir2p has been questioned (Anderson et al., 2003; Kaeberlein et al., 2004; Grubisha et al., 2005).

Chronological ageing in yeast has been used as a valuable model to study oxidative damage and ageing of the postmitotic tissues of higher organisms (Sinclair, 2002; MacLean et al., 2001). In post-diauxic cultures, respiration is the main source of energy for the yeast cell. It is obtained from previously stored nutrients such as glycogen and trehalose. The cell wall thickens and cells become more resistant to heat and oxidative stresses. Chronological 
life-span extension is highly dependent on stress resistance (Fabrizio et al., 2001) and has been observed under calorie restriction (Fabrizio et al., 2004; Reverter-Branchat et al., 2004) and in cells overexpressing superoxide dismutase (Sod)2p (Harris et al., 2003).

Replicative and chronological ageing show markers of oxidative stress and selective oxidative modification of proteins. These major protein targets have been identified as enzymes of glucose and energy metabolism, as well as stress resistance and cytoskeletal proteins (ReverterBranchat et al., 2004). Such oxidative damage to proteins and other stress markers are reduced in cells cultured under calorie restriction.

In this context, one could ask whether the impairment of a given protein function caused by such modifications (i) actively contributes to the ageing phenotype, (ii) is merely a consequence of the ageing process or (iii) has been evolutionarily favoured (e.g. impairment of glycolytic flux to favour the pentose phosphate pathway under stress conditions). Whichever is the case, one might think that the preservation of cell viability would be the main goal. With the aim of getting an insight into question (i) above, we prepared strains that overproduced one of these target proteins and analysed the impact of this extra dose on life span. In other words, is the additional activity of a particular protein advantageous or detrimental to cell life span?

We have previously reported that one of the oxidatively modified targets is alcohol dehydrogenase 1 (Adh1)p (Reverter-Branchat et al., 2004). This enzyme is involved in glucose metabolism in S. cerevisiae, and catalyses the conversion of acetaldehyde to ethanol by a concomitant conversion of $\mathrm{NADH}$ into $\mathrm{NAD}^{+}$, thus contributing to balancing the levels of the oxidized cofactor. As a consequence of decreased enzymic activity, the steady state of $\mathrm{NAD}^{+} / \mathrm{NADH}$ levels would vary. Such variation would affect the activity of Sir2p, thus affecting life span. For these reasons we focused our investigation on cells possessing an extra copy of the dehydrogenase gene. The results presented in this paper provide evidence that this strain shows extended replicative and chronological life span. Responses to mild endogenous oxidative stress in combination with an increased activity of Sir $2 p$ are the main traits responsible for the life-span lengthening observed.

\section{METHODS}

Organisms and culture conditions. Strains used in this work are listed in Table 1. S. cerevisiae CML128 (MATa ura3-52 his4 leu2-3,112 $\operatorname{trp1)}$ was used as a parental wild-type (WT) strain (Gallego et al., 1997). The strain GRB2402 carried a second copy of the ADH1 gene in the genome. This strain was constructed by integrating plasmid pTB106 in the chromosome at the LEU2 locus after ClaI-mediated linearization of the plasmid. Plasmid pTB106 was constructed as follows. The $A D H 1$ gene product was obtained using the oligonucleotides ADH1F (GACACCCGGGTTCAATTCATTTGGGTGTGC) and ADH1R (GACAGAATTCCTGAAGGCTAGGCTGTGGA), and was subsequently cloned into the EcoRI and SmaI sites of the Yiplac128 vector. The strain GRB2401 was obtained by integrating the empty Yiplac128 vector in CML128. Deletion of the SIR2 gene was obtained by replacing the ORF with a kanMX cassette system using p43965, a pUG26-derived vector (from the Euroscarf collection), digested with NotI. Strains GRB2401UT and GRB2402UT were constructed by transformation with plasmid pADH4UCA-IV (a kind gift of D. Gottschling, Fred Hutchinson Cancer Research Center) in GRB2401 and GRB2402 backgrounds, respectively. Plasmid pADH4UCA-IV, containing the URA3 reporter gene, was digested wtih SalI and EcoRI prior to transformation, and was integrated into the subtelomeric region of chromosome VII as described elsewhere (Gottschling et al., 1990).

Yeast cells were grown aerobically at $30{ }^{\circ} \mathrm{C}$ in rich YPD medium $(1 \%$ yeast extract, $2 \%$ peptone, $2 \%$ glucose) or in YPG medium ( $1 \%$ yeast extract, $2 \%$ peptone, $3 \%$, v/v, glycerol) by incubation in a rotary shaker at $30{ }^{\circ} \mathrm{C}$. Glucose synthetic medium (SC) contained $2 \%$ glucose, $0.67 \%$ yeast nitrogen base (Difco, without amino acids), the required auxotrophic supplements plus drop-out mixture (Kaiser et al., 1994).

\begin{abstract}
Western blot analysis. Cell extracts were obtained as described by Rodriguez-Manzaneque et al. (1999), separated in SDS-polyacrylamide gels and transferred to PVDF membranes. The following antibodies were used: anti-Adh (1:400 000 dilution; Chemicon), antiaconitase (1:2000 dilution; a gift from R. Lill, Philipps-Universität Marburg), anti- $\alpha$-ketoglutarate dehydrogenase $[1: 5000$ dilution;
\end{abstract}

Table 1. Yeast strains used in this study

\begin{tabular}{|c|c|c|c|}
\hline Strain & Genotype & Comments & Source \\
\hline CML128 & MATa, ura3-52 his4 leu2-3,112 trp1 & WT & Gallego et al. (1997) \\
\hline GRB2401 & CML128 LEU2 & Integration of empty YIplac128 in CML128 (WT) & This study \\
\hline GRB2402 & CML128 LEU2, ADH1 & $\begin{array}{l}\text { Integration of YIplac128 with } A D H 1 \text { in CML128 } \\
(2 \times A D H 1)\end{array}$ & This study \\
\hline GRB2403 & GRB2401 LEU2, sir2:: $k a n^{\mathrm{R}}$ & Deletion of SIR2 in GRB2401 (WT sir2A) & This study \\
\hline GRB2404 & GRB2402, LEU2, ADH1, sir2:: kan ${ }^{\mathrm{R}}$ & Deletion of SIR2 in GRB2402 $(2 \times A D H 1$ sir2 $\Delta)$ & This study \\
\hline GRB2401UT & GRB2401, LEU2, adh4:: URA3-TEL (VII-L) & $\begin{array}{l}\text { Integration of adh4:: URA3-TEL (VII-L) in GRB2401 } \\
\text { (WT-UT) }\end{array}$ & This study \\
\hline GRB2402UT & $\begin{array}{l}\text { GRB2402 LEU2, ADH1, adh4:: URA3-TEL } \\
(\text { VII-L) }\end{array}$ & $\begin{array}{l}\text { Integration of } a d h 4:: \text { URA3-TEL (VII-L) in GRB2402 } \\
(2 \times A D H 1-\mathrm{UT})\end{array}$ & This study \\
\hline
\end{tabular}


raised in rabbit as described by Cabiscol et al. (2002)], antimitochondrial porin ( $1: 1000$ dilution; Molecular Probes), anti-Ssa (1:600 dilution; EAC), anti-Ssb (1:600 dilution; EAC), anti-Hsp104 (1:5000 dilution; StressGen), anti-Hsc90 (1:10000 dilution; a gift of S. Lindquist, Whitehead Institute of Biomedical Research), and antiHsp60 (1:8000 dilution; StressGen). Secondary antibodies conjugated to horseradish peroxidase were used as follows: goat anti-mouse antibody (1:2500 dilution; Pierce), donkey anti-rabbit antibody (1:12500 dilution; Amersham) and rabbit anti-goat antibody ( $1: 25000$ dilution; Pierce).

Enzyme activities. Cell extracts were obtained using glass beads. Catalase activity was measured as described by Jakubowski et al. (2000). Sod (Sod1 and Sod2) and Adh activities were assayed by chromogenic staining (zymogram), as described in Luk \& Culotta (2001) (Sod) and Williamson et al. (1980) (Adh).

Life-span determination. To measure chronological life span, exponential-phase cells $\left(2 \times 10^{7}\right.$ cells $\left.\mathrm{ml}^{-1}\right)$ incubated in YPD medium were regarded as day 0 . To determine the age-dependent mortality, cell viability at different days of growth was compared by spreading serial dilutions $(1: 10)$ of the cultures on solid YPD plates followed by incubation at $30{ }^{\circ} \mathrm{C}$ for 3 days. Replicative life-span determinations were performed by micromanipulation, as described elsewhere (Smith \& Boeke, 1997; Sinclair \& Guarente, 1997), using a Singer MSM system 300 micromanipulator. Life-span analyses wer carried out on YPD plates twice independently with 60 cells per strain per experiment. Cells that never budded were excluded from analysis.

Silencing assay. Telomeric URA3 reporter strains GRB2401UT (WT-UT) and GRB2402UT $(2 \times A D H 1-U T)$ were assayed for Sir2psilencing activity. Cells were grown at $30{ }^{\circ} \mathrm{C}$ in SC medium plus uracil

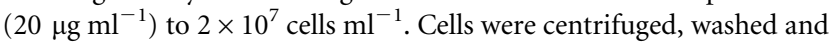
diluted 1:10 in SC medium lacking uracil, with or without the Sir2p inhibitors splitomicin $(5 \mu \mathrm{M})$ or nicotinamide (NAM; $1 \mathrm{mM}$ ). Growth was measured and the duplication time calculated after a $1 \mathrm{~h}$ adaptation period.

Analysis. Ethanol concentration was analysed enzymically in cell-free culture media obtained at different times of growth, from exponential to diauxic phase (2 days) using the Ethanol UV test (Roche Diagnostics). Resistance to $\mathrm{H}_{2} \mathrm{O}_{2}$ or heat shock was tested on cells grown on YPD or YPG media. At the middle of exponential phase $\left(2 \times 10^{7}\right.$ cells ml $\left.^{-1}\right)$, cells were either changed to $48{ }^{\circ} \mathrm{C}$ and incubated for 10,20 and $30 \mathrm{~min}$, or treated with $\mathrm{H}_{2} \mathrm{O}_{2}$ for $60 \mathrm{~min}$ at the required concentration. Viability was measured by plating 0.1 and $0.2 \mathrm{ml}$ of culture dilution on YPD plates and counting survivor colonies after 2 days at $30{ }^{\circ} \mathrm{C}$. Levels of $\mathrm{NAD}^{+}$and NADH were measured as described by Ashrafi et al. (2000). Total cellular iron was determined under reducing conditions with bathophenanthroline sulfonate as chelator (Tamarit et al., 2006). Superoxide ion levels were measured in a spectrofluorophotometer (RF-5000, Shimadzu). Exponentially growing cells were washed in water and resuspended in PBS plus $0.1 \%(\mathrm{v} / \mathrm{v})$ glycerol and the superoxide-specific probe dihydroethidium (DHE; $5 \mu \mathrm{g} \mathrm{ml}^{-1}$ ) (Fluka) (Aguilaniu et al., 2003). The rate of oxidation of DHE was calculated from the rate of increase in fluorescence for $30 \mathrm{~min}$ (excitation $520 \mathrm{~nm}$, emission $590 \mathrm{~nm}$ ). Oxygen consumption was measured in a Clark detector, as described by Brown \& Cooper (1995). In brief, oxygen uptake was measured in a $4 \mathrm{ml}$ stirred chamber (100 r.p.m.) using a YSI 53 biological oxygen monitor (Yellow Springs Instruments) following the manufacturer's directions. A volume containing $1 \times 10^{7}$ cells grown in YPD was harvested at mid-exponential phase, washed, resuspended in fresh YPD medium and tested for oxygen consumption. Results shown represent the mean \pm SEM of three experimental trials.
RESULTS

\section{Cells with an extra copy of ADH1 display chronological life-span extension}

During ageing, oxidation (and inactivation) of a given protein could be either deleterious or protective for the cell. In a previous work (Reverter-Branchat et al., 2004), our group has demonstrated that several glycolytic enzymes (Adh1p, enolase, glyceraldehyde-3-phosphate dehydrogenase, pyruvate decarboxylase and fructose-1,6-bisphosphate aldolase) are oxidatively damaged during yeast ageing (both chronological and replicative). In order to investigate the effect of an increased amount of a given protein in the ageing process and stress resistance, we constructed a strain carrying an extra copy of the $A D H 1$ gene. When cells with an extra copy of $A D H 1$ were cultured in YPD media they effectively expressed $70 \%$ more Adh1p (Fig. 1a) and, accordingly, the activity was increased by $60 \%$ (Fig. 1b) compared to the WT strain carrying the empty plasmid. The introduction of the extra copy did not affect the duplication time, which was $90 \mathrm{~min}$ in both strains.

To measure the effect of this extra dose on ageing, chronological life span was determined. Chronological life span in S. cerevisiae is defined as the time for which cells in stationary-phase culture remain viable, and has been proposed as a model for the ageing of post-mitotic tissues in mammals. Resistance to oxidative stress plays a preponderant role in the increase in survival in stationary phase (Harris et al., 2005). The viability of the WT and $2 \times A D H 1$ strains was monitored for 70 days. As shown in Fig. 1(c), survival declined after day 30 for WT cells, while such a decline was not observed until day 40 for the $2 \times A D H 1$ strain.

In order to explain the extended viability in stationary phase, resistance to oxidative stress was analysed in both strains. WT and $2 \times A D H 1$ cells were grown exponentially in YPD, challenged with several $\mathrm{H}_{2} \mathrm{O}_{2}$ concentrations for $1 \mathrm{~h}$, and viability assays were performed. Fig. $1(\mathrm{~d})$ indicates that the $2 \times A D H 1$ strain was clearly more resistant than WT. The increased resistance to oxidative stress observed during exponential phase by the $2 \times A D H 1$ cells extended into stationary phase, since cells from 25 days of culture showed higher resistance to $\mathrm{H}_{2} \mathrm{O}_{2}$ than WT cells (data not shown). Additionally, cell survival after heat stress $\left(48{ }^{\circ} \mathrm{C}\right)$ was also increased in the $2 \times A D H 1$ strain (Fig. 1e).

Growth on a respiratory carbon source such as glycerol (YPG medium) can be used as an internal control, since the activity of Adhlp as a fermentative enzyme is dispensable. When both strains were grown exponentially in YPG, no differences were observed when the cultures were challenged with $\mathrm{H}_{2} \mathrm{O}_{2}$, indicating that the different phenotype was due to the increased Adh activity (data not shown).

\section{Antioxidant enzymes are induced in $2 \times A D H 1$ cells}

We next measured the level of enzymes mainly involved in oxidative stress resistance (Fig. 2a). Catalase activity 
(a)

Anti-ADH

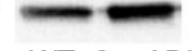

WT $2 \times A D H 1$

(b)

ADH1 activity

WT $2 \times A D H 1$ (c)

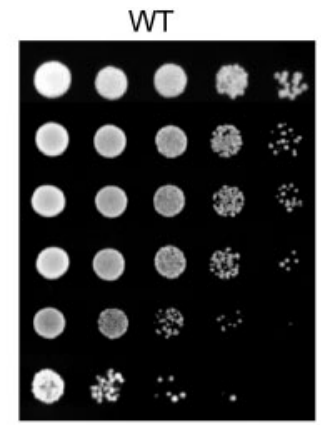

$2 \times A D H 1$

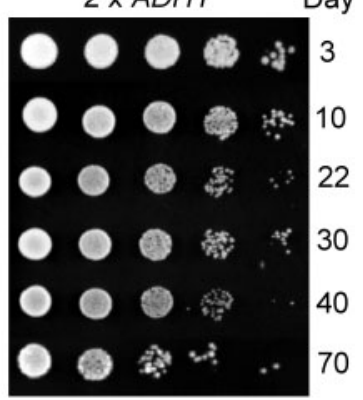

(d)

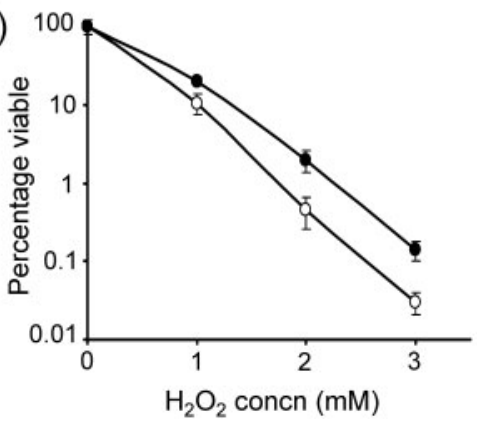

(e)

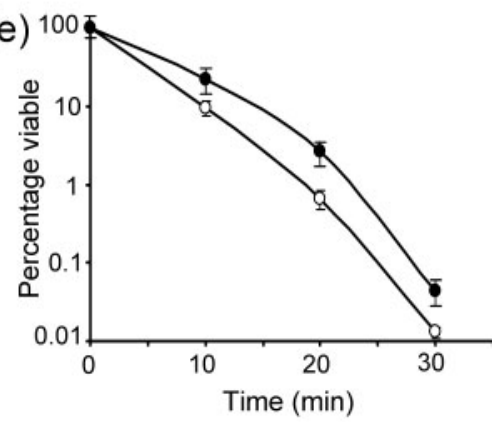

Fig. 1. Effect of extra $A D H 1$ dosage on chronological ageing and stress resistance. Cells from WT and $2 \times A D H 1$ strains were first tested for Adh1 protein (a) and activity levels (b) present in crude extracts obtained from cells grown in YPD. (c) Survival of WT and $2 \times A D H 1$ cells grown on YPD at the indicated days of culture. Viability was measured by plating serial dilutions (1:10) on YPD plates. (d) Resistance to $\mathrm{H}_{2} \mathrm{O}_{2}$ treatment for 60 min. (e) Resistance to heat stress $\left(48{ }^{\circ} \mathrm{C}\right.$ for 10,20 and $\left.30 \mathrm{~min}\right)$. In (d) and (e), cell viability was measured by counting survivor colonies $(\bigcirc, \mathrm{WT} ; \bullet$, $2 \times A D H 1$ ). Data are presented as mean $\pm \mathrm{SD}$ from three independent experiments. was $40 \%$ higher in $2 \times A D H 1$ cells compared to WT when grown in YPD. Sod1 (cytosolic, $\mathrm{Cu} / \mathrm{Zn}$-dependent) and Sod2 (mitochondrial, Mn-dependent) activities measured in these strains were also 30 and 50\% higher, respectively. These results could explain the increased resistance to both oxidative and heat stresses, since there is a well-known cross-protection effect mediated by several stress transcription factors (Martinez-Pastor et al., 1996; Schmitt \& McEntee, 1996). The increased catalase activity observed in the $2 \times A D H 1$ cells when grown exponentially was also observed at stationary phase, since cells from 3 to 25 days of culture showed higher catalase

(a)
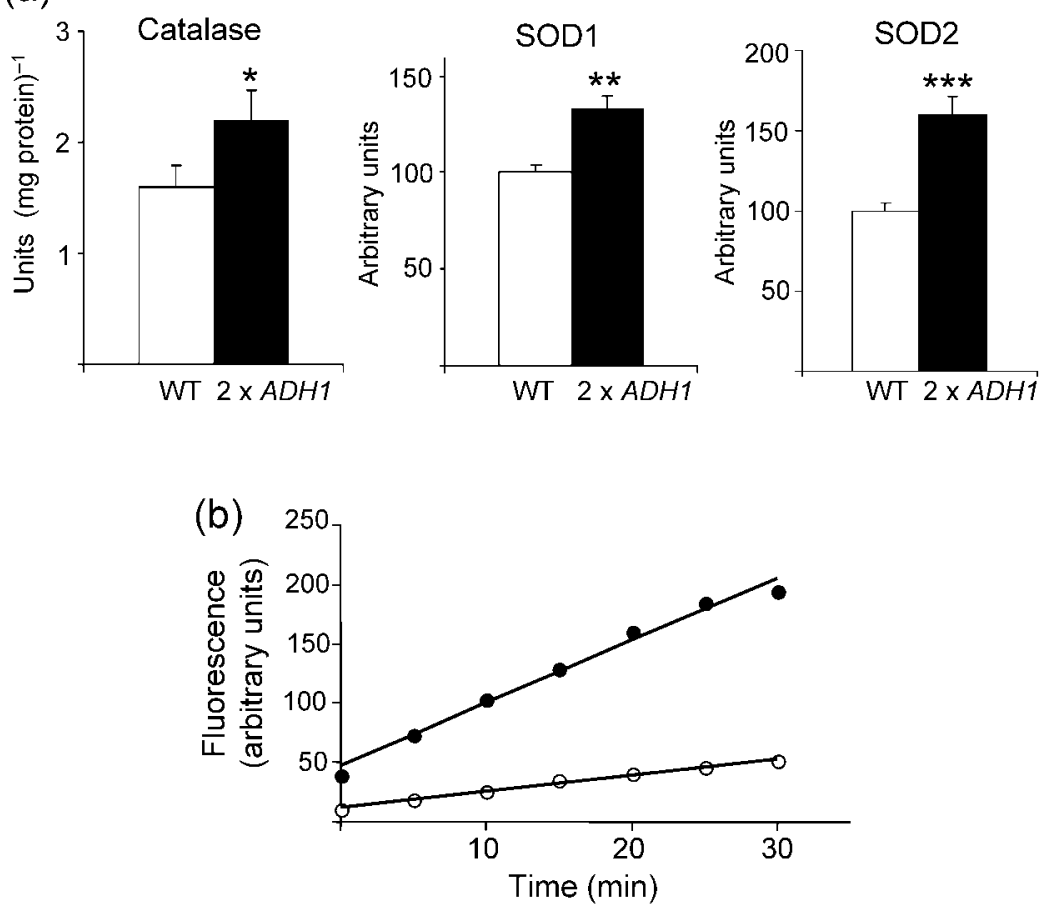

Fig. 2. Activities of antioxidant enzymes and superoxide levels in $2 \times A D H 1$ cells. Cultures of WT and $2 \times A D H 1$ were grown exponentially in YPD medium and activities analysed in cell extracts. (a) Catalase activity ( $\mu \mathrm{mol} \mathrm{min}^{-1}$ $\mathrm{mg}^{-1}$ ) was determined spectrophotometrically, and Sod 1 and Sod 2 activities were analysed in native gels. Bands corresponding to $\mathrm{Cu} / \mathrm{Zn}$ Sod (Sod1) and Mn-Sod (Sod2) were measured with a densitometer and the relative intensities calculated (Quantity One software, Bio-Rad). Data are presented as means \pm SD of three independent experiments. Statistical comparisons between $2 \times A D H 1$ and WT were done using Student's $t$ test $\left({ }^{\star} P=0.032\right.$; ${ }^{* \star} P=0.0017 ;{ }^{* \star *} P=0.0013$ ). (b) Cultures of WT and $2 \times A D H 1$ were loaded with $5 \mu \mathrm{g} \mathrm{DHE}$ $\mathrm{ml}^{-1}$ and the rate of DHE oxidation by endogenous superoxide was measured at different times $(\bigcirc, \mathrm{WT} ; \bigcirc, 2 \times A D H 1)$. Results are given as the mean of three independent experiments. 
activity ( $230 \%$ more) compared to WT cells (data not shown).

An endogenous oxidative stress would be the explanation for the increased antioxidant capacity observed in $2 \times A D H 1$ cells. Thus, we measured the steady-state levels of superoxide anions inside the cells. As shown in Fig. 2(b), the rate of oxidation of DHE, a superoxide-specific probe, was increased fourfold in $2 \times A D H 1$ cells. Such differences were abrogated when cells were grown in YPG media (data not shown).

The fact that the catalytic activity of Adh1p generates ethanol opened the possibility that these cells carrying an extra copy of $A D H 1$ were under ethanol stress (Piper, 1995). In this context, it has been reported that translocation of Msn2 to the nucleus upon environmental ethanol stress triggers the expression of resistance genes (van Voorst et al., 2006). As shown in Fig. 3(a), the ethanol concentration present in the culture media from exponential to diauxic phase was the same in both strains. In addition, quantification by Western blotting of several heat-shock proteins, known to be induced during ethanol stress (Piper, 1995), showed no difference (Fig. 3b).

Mitochondria are the primary site of reactive oxygen species (ROS) generation; thus, an increase in either the activity or the number of mitochondria could be the origin of the stress. Oxygen consumption has been used as a measure of respiratory chain activity and can be checked by using a Clark electrode. As shown in Fig. 4(a), a $25 \%$ increase in oxygen consumption was observed in $2 \times A D H 1$ compared to the WT strain.

Since the number of mitochondria could affect the oxygen consumption, we analysed the amount of several mitochondrial proteins as an indirect measure of the number of mitochondria. Although a slight increase (around 15\%) in mitochondrial Hsp60 was detected, no differences were observed in aconitase, $\alpha$-ketoglutarate dehydrogenase and the mitochondrial outer-membrane porin when compared with the amounts present in WT cells (Fig. 4b). These (a)

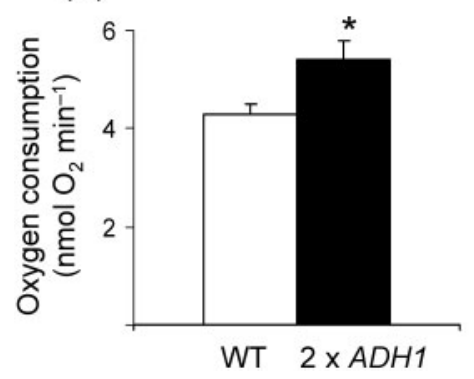

(b)

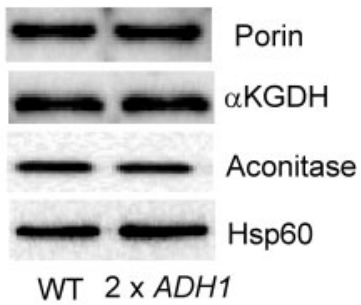

Fig. 4. Effect of an extra copy of adh1 on oxygen consumption and amounts of mitochondrial proteins. Cultures of WT and $2 \times A D H 1$ were grown exponentially in YPD medium. (a) Oxygen consumption ( $\mathrm{nmol} \mathrm{O}_{2} \mathrm{~min}^{-1}$ ) was measured by a Clark electrode. Data are presented as means \pm SD of three independent experiments. Statistical comparison between $2 \times A D H 1$ and WT was done using Student's $t$ test $\left({ }^{\star} P=0.0062\right)$. (b) The amounts of four mitochondrial proteins [outer-membrane porin, $\alpha$-ketoglutarate dehydrogenase $(\alpha \mathrm{KGDH})$, aconitase and Hsp60] were assessed by immunoblotting analysis.

results ruled out the possibility that an increased number of mitochondria was responsible for increased oxygen consumption.

\section{Strains carrying an extra ADH1 copy show extended replicative life span and increased Sir2p activity}

Replicative life span has been defined as the number of buds generated by a dividing individual mother. The increased activity of Adh1p in $2 \times A D H 1$ cells would vary the $\mathrm{NAD}^{+} / \mathrm{NADH}$ ratio. This ratio has been demonstrated to have effects on Sir2 activity and, consequently, on replicative life span. The mean and maximum life span can be quantified by micromanipulation experiments. As shown in Fig. 5(a), mean life span increased $30 \%$ in the

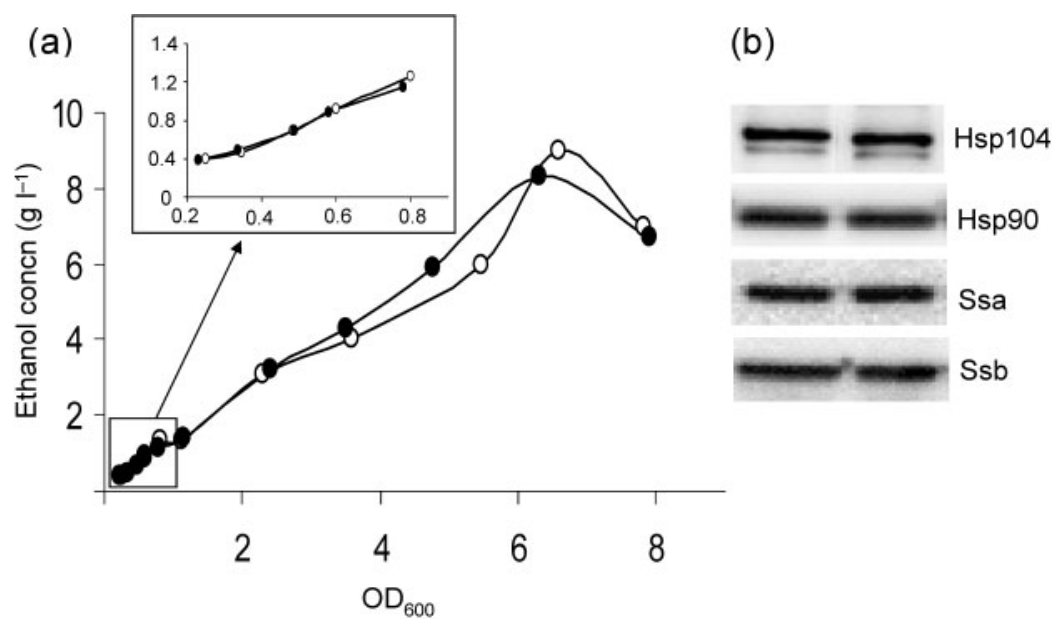

Fig. 3. Ethanol production in $2 \times A D H 1$ cells. (a) The ethanol concentration in cell-free culture media was measured in WT $(\bigcirc)$ and $2 \times A D H 1(0)$ cells at different times of growth. The inset shows the production of ethanol in exponential phase in more detail. (b) Amounts of heat-shock proteins Hsp104, Hsp90 and two types of Hsp70 (Ssa and Ssb) were assessed by immunoblotting analysis. 

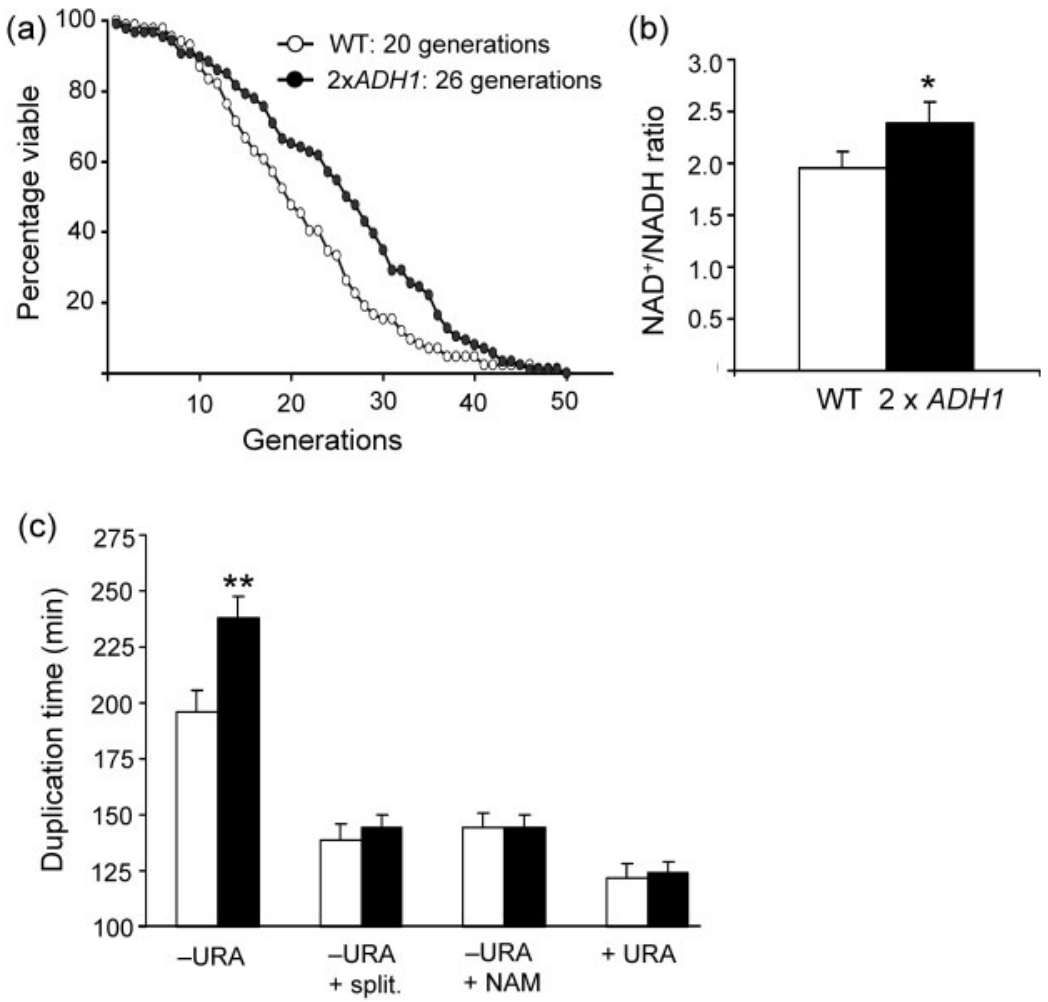

Fig. 5. Effect of extra $A D H 1$ dosage on replicative ageing and the role of Sir2p. The replicative ageing assay (a) was performed by micromanipulation and the mean life span was determined ( $\bigcirc, W T, 20$ generations; $\bullet$, $2 \times A D H 1,26$ generations). The $\mathrm{NAD}^{+} / \mathrm{NADH}$ ratio (b) was analysed in cells of WT and $2 \times A D H 1$ strains grown exponentially in YPD. Sir2 activity (c) was assessed in WT-UT (white bars) and $2 \times A D H 1-U T$ (black bars) strains. Duplication time in synthetic medium lacking uracil with or without the Sir2p inhibitors splitomicin (split.; $5 \mu \mathrm{M}$ ) or NAM ( $1 \mathrm{mM}$ ) was measured. Data are presented as mean \pm SD from three separate experiments. Statistical comparisons between $2 \times A D H 1$ and WT were done using Student's $t$ test $\left({ }^{\star} P=0.041\right.$; ${ }^{\star *} P=0.0096$ ).
$2 \times A D H 1$ cells compared to WT (20 generations for WT and 26 for $2 \times A D H 1$ cells).

As shown in Fig. $5(\mathrm{~b})$, the $\mathrm{NAD}^{+} / \mathrm{NADH}$ ratio in the $2 \times A D H 1$ strain was increased by $20 \%$ compared to that of WT cells grown in YPD. Consistently, cells grown in YPG showed a twofold increase in the $\mathrm{NAD}^{+} / \mathrm{NADH}$ ratio with respect to YPD-grown cells, but no differences were observed between the two strains (data not shown). To analyse whether a $20 \%$ increase in $\mathrm{NAD}^{+} / \mathrm{NADH}$ ratio could affect Sir2 activity, we constructed the strains GRB2401UT (WT-UT) and GRB2402UT $(2 \times A D H 1-$ UT). They had the URA3 reporter gene integrated into the subtelomeric region of chromosome VII-L, thus allowing for efficient determination of Sir2-dependent telomeric silencing (Aparicio \& Gottschling, 1994). Because Ura3p is required for uracil biosynthesis, the more silenced the telomeric URA3 gene (higher Sir2 activity) the slower the growth in medium lacking uracil. Fig. 5(c) shows that the duplication times of WT-UT and $2 \times A D H 1$-UT grown on SC medium were 196 and $238 \mathrm{~min}$, respectively. To demonstrate that this difference in duplication time was Sir2p-dependent, the addition of two well-known Sir2p inhibitors, splitomicin (Bedalov et al., 2001) and NAM (Bitterman et al., 2002; Jackson et al., 2003) was used. Derepression of the URA3 reporter should result in growth enhancement on medium lacking uracil. Addition of $5 \mu \mathrm{M}$ splitomicin or $1 \mathrm{mM}$ NAM to the medium abrogated the differences in duplication time observed between WT-UT and $2 \times A D H 1-U T$. With these treatments, cells grew almost as fast as in synthetic medium plus uracil; no differences were observed between the two strains (duplication times of 120 and $122 \mathrm{~min}$, respectively) (Fig. 5c).

\section{Sir2-mediated oxidative-stress resistance}

Could Sir $2 \mathrm{p}$ mediate the resistance to oxidative stress observed in $2 \times A D H 1$ cells? In fact, mammalian cells respond to oxidative stress by the formation of complexes between Sirtlp, the orthologue of Sir2p, and members of forkhead transcription factors (FOXOs) (Brunet et al., 2004; Kobayashi et al., 2005). Such interaction allows these factors to control various biological functions, including detoxification of ROS (Kops et al., 2002). To answer the above question, the SIR2 gene was deleted in the WT and $2 \times A D H 1$ background cells to obtain the corresponding sir2 $\Delta$ derivatives. Fig. 6(a, b) shows that GRB2403 (WT sir2 $\Delta$ ) and GRB2404 $(2 \times A D H 1 \operatorname{sir} 2 \Delta)$ displayed the same resistance to both oxidative and heat stresses. Accordingly, when catalase activity was measured in these strains grown at exponential phase, no significant difference was observed (Fig. 6c). Additionally, catalase activity in both strains showed no significant difference in stationary phase (data not shown). These results indicated that the increased antioxidant capacity (and consequently higher survival in stationary phase) was a SIR2-dependent process in $2 \times A D H 1$ cells.

\section{DISCUSSION}

Adhlp is a dehydrogenase that catalyses the final step of glucose fermentation, producing ethanol and regenerating 


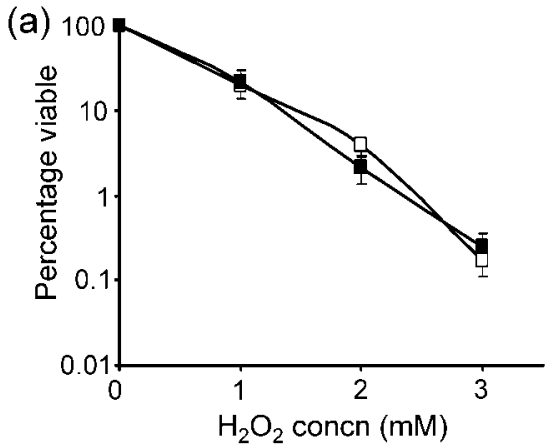

(b)
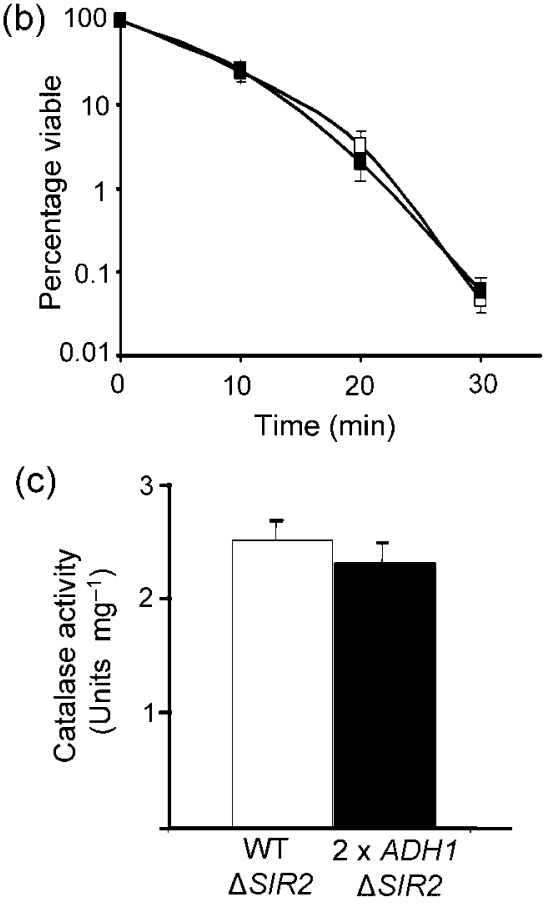

Fig. 6. Sir2 and oxidative stress. Resistance of WT sir2 $\Delta$ ( $\square$ ) and $2 \times A D H 1$ sir2 $\triangle(\mathbb{\square})$ cells grown on YPD medium to oxidative and heat stresses. (a) $\mathrm{H}_{2} \mathrm{O}_{2}$ treatment for $60 \mathrm{~min}$; (b) incubation at $48{ }^{\circ} \mathrm{C}$ for 10,20 and 30 min. Viability was measured by counting survivor colonies on YPD plates. (c) Cultures of WT sir2 $\Delta$ and $2 \times A D H 1$ sir2 $\Delta$ were grown exponentially in YPD medium, and catalase activity ( $\mu \mathrm{mol} \mathrm{min}^{-1} \mathrm{mg}^{-1}$ ) was determined. Data are presented as means $\pm S D$ of three independent experiments.

the oxidized coenzyme $\mathrm{NAD}^{+}$. The role of Adh1p on yeast ageing was explored by construction of a strain that carried an additional copy of the $A D H 1$ gene under the control of its own promoter. The strain expressed $70 \%$ more protein than a WT strain carrying the empty plasmid and had $\sim 60 \%$ more activity. Initial results showed that this strain was resistant to both oxidative and heat stresses by moderate increases in catalase, Sod1p and Sod2p. In contrast, strains carrying an extra copy of one of the genes coding for proteins that are also targets of oxidative stress, such as enolase, pyruvate decarboxylase and fructose-1,6bisphosphate aldolase (Reverter-Branchat et al., 2004), did not display such a phenotype (data not shown).
Chronological life-span extension has been related to antioxidant activity in stationary phase (Fabrizio et al., 2001; Fabrizio \& Longo, 2003). Given the characteristics described for $2 \times A D H 1$ cells, survival on stationary phase could be a consequence of such resistance. The data presented here on stress resistance show that cells adapted to increased respiratory conditions are more stress resistant in both exponential and stationary phase, and show extended chronological life span (MacLean et al., 2001). It has also been reported that SOD2 overexpression (10fold normal levels) increases yeast chronological life span (Harris et al., 2003), although replicative life span is shortened due to defects in mitochondrial segregation. Such life-span reduction is independent of Sir2p. In our model, these problems were not observed, probably because in $2 \times A D H 1$ cells only a mild increase in Sod1p and Sod $2 \mathrm{p}$ was observed. In addition, these cells induced not only Sod2p but a balanced set of antioxidant enzymes.

The data for DHE oxidation also indicated the existence of an endogenous oxidative stress in $2 \times A D H 1$ cells. Iron, as a prooxidant metal, was also measured as a possible inducer of oxidative stress. Total iron values measured in cultures of WT and $2 \times A D H 1$ cells grown in YPD at exponential phase as well as during stationary phase were indistinguishable (data not shown). How can the increased Adh1 activity generate such a mild stress situation? An ethanol stress was ruled out by experimental data (Fig. 3a, b). One possible explanation relies on the existence of the ethanol/ acetaldehyde shuttle (Lin \& Guarente, 2003; Bakker et al., 2001). According to this pathway, some of the ethanol produced by glycolysis diffuses across the mitochondrial membrane. In the matrix, mitochondrial dehydrogenases oxidize ethanol, with a concomitant conversion of $\mathrm{NAD}^{+}$ to $\mathrm{NADH}$, which, in turn, is then oxidized to $\mathrm{NAD}^{+}$by the electron transport chain. Increased Adh1 activity would therefore raise the activity of this shuttle and, as a result, a rise in oxygen consumption in these cells should be observed (Fig. 4a) as well as increased ROS production (as detected by DHE oxidation). Another possibility to explain the observed phenotype (increased oxygen consumption, oxidant resistance, and chronological and replicative life span) is that $2 \times A D H 1$ cells have lowered catabolite repression. A similar situation is observed under calorie restriction when yeast is switched from 2 to $0.5 \%$ glucose, generating increased respiration and therefore an increased $\mathrm{NAD}^{+} / \mathrm{NADH}$ ratio (Lin et al., 2002).

In any case, the fact that replicative life span was increased in the $2 \times A D H 1$ cells seems, a priori, to be a consequence of the increased $\mathrm{NAD}^{+} / \mathrm{NADH}$ ratio. It is worth pointing out that replicative life span increased $\sim 30 \%$, a value quite similar to that reported for cells grown under calorie restriction (Lin et al., 2002). However, since the increase in $\mathrm{NAD}^{+} / \mathrm{NADH}$ ratio observed in cells with an extra copy of $A D H 1$ was moderate, testing Sir2 activity seemed relevant to support the results obtained. This was carried out by measuring silencing in cells in which the URA3 reporter gene was located in the telomere, under Sir2p regulation. 
Duplication time was $20 \%$ slower in the $2 \times A D H 1$ strain, and this difference was abolished when splitomicin or NAM was added to the culture. The specificity of these inhibitors indicated that the difference was due to higher Sir2p activity.

The results obtained from the sir $2 \Delta$ strains (WT sir $2 \Delta$ and $2 \times A D H 1$ sir $2 \Delta$ ) indicate that the response to mild oxidative stress is mediated by Sir $2 \mathrm{p}$. In contrast to the differences observed between WT and $2 \times A D H 1$ cells, the derivative strains lacking SIR2 showed the same catalase activity and, accordingly, the same survival after $\mathrm{H}_{2} \mathrm{O}_{2}$ treatment. How can SIR2 be involved in a response to the mild oxidative stress observed in the $2 \times A D H 1$ strain? In $S$. cerevisiae, adaptation to $\mathrm{H}_{2} \mathrm{O}_{2}$ correlates with the rapid induction of a so-called $\mathrm{H}_{2} \mathrm{O}_{2}$ stimulon of several hundred proteins (Godon et al., 1998) and the repression of many others. This adaptation is orchestrated by the action of several transcriptional regulators, such as Msn2/Msn4 (Hasan et al., 2002), Yap1 and Skn7 (Kuge \& Jones, 1994; Krems et al., 1996). To our knowledge, there are no reports connecting Sir2p with the activation of such transcription factors in yeast. However, in mammalian cells, Sirt1p, the mammalian orthologue of Sir2p, interacts with and deacetylates FOXOs (Brunet et al., 2004; Van der Horst et al., 2004). These factors enter the nucleus under stress conditions. As a consequence, they transactivate a series of target genes that have critical roles in the cellular response to ROS detoxification by inducing Sod1p and Sod2p, and catalase (Kops et al., 2002; Nemoto \& Finkel, 2002; Giannakou \& Partridge, 2004). Since the S. cerevisiae genome has four FOXOs (FKH1, FKH2, FHL1 and HCM1), it could be that the increased amount of Sir2p observed enhances the deacetylation of such forkheads. As a result, activation of genes having critical roles in ROS detoxification, such as catalase and Sods, could occur. This possibility needs to be explored. However, because $2 \times A D H 1$ cells present a change in redox state, the role of Yap1, which is regulated through thiol oxidation/ reduction (Delaunay et al., 2000), also merits future experimental work.

Our results concerning increased replicative and chronological life span seem to be in contradiction with observations reported by V. D. Longo and colleagues (Fabrizio et al., 2005). They showed that deletion of SIR2 increases stress resistance and concluded that the effects of SIR2 on chronological life span are opposite to those on replicative life span. One of the consequences of SIR2 deletion, among others, is a substantial increase in mutation frequency. Such problems may activate a pathway of oxidative-stress resistance, and this is clear by a comparison of the geneexpression profiles between sir $2 \Delta$ and WT cells (Fabrizio et al., 2005). In fact, our observations in the WT sir2 $\Delta$ strain also confirm a moderately higher stress resistance, at exponential phase, compared to the original WT strain. However, this does not necessarily mean that SIR 2 reduces stress resistance. In fact, $2 \times S I R 2$ cells have been described as more resistant when submitted to heat shock (Anderson et al., 2002). Probably, the increased stress resistance observed in both sir $2 \Delta$ and $2 \times S I R 2$ cells is a consequence of the activation of different pathways.

Regarding the question about the relationship between oxidative modification and ageing, it seems clear that oxidative damage of Adh1p contributes to the ageing phenotype. The relevance of maintaining Adh1p activity is to maintain the $\mathrm{NAD}^{+} / \mathrm{NADH}$ ratio, which in turn contributes to the maintenance of Sir2 activity. Although the results shown in this paper have been obtained with an overdose of $A D H 1$, of which the only known function is to participate in the fermentative metabolism of glucose, it is not purely speculative to infer from these results that the impairment of any enzyme that participates in $\mathrm{NAD}^{+} /$ NADH balancing will actively affect cell ageing.

\section{ACKNOWLEDGEMENTS}

We thank Vanessa Guijarro for technical assistance. We are indebted to P. W. Piper (University of Sheffield) for training G. R.-B. in replicative life-span techniques using the Singer MSM 300. We thank Enrique Herrero (Universitat de Lleida) for critical review of the manuscript. We are also grateful to Montse Rué (Universitat de Lleida) for helpful assistance in statistical analysis. This work has been supported by grants BFU2004-00593/BMC from the Ministerio de Educación y Ciencia (Spain) and SGR2005-00677 from the Generalitat de Catalunya. G. R.-B. and M.A.S. are recipients of $\mathrm{PhD}$ fellowships from the Ministerio de Educación y Ciencia (Spain).

\section{REFERENCES}

Aguilaniu, H., Gustafsson, L., Rigoulet, M. \& Nyström, T. (2003). Asymmetric inheritance of oxidatively damaged proteins during cytokinesis. Science 299, 1751-1753.

Anderson, R. M., Bitterman, K. J., Wood, J. G., Medvedik, O., Cohen, H., Lin, S. S., Manchester, J. K., Gordon, J. I. \& Sinclair, D. A. (2002). Manipulation of a nuclear $\mathrm{NAD}^{+}$salvage pathway delays aging without altering steady-state $\mathrm{NAD}^{+}$levels. J Biol Chem 277, 18881-18890.

Anderson, R. M., Latorre-Esteves, M., Neves, A. R., Lavu, S., Medvedik, O., Taylor, C., Howitz, K. T., Santos, H. \& Sinclair, D. A. (2003). Yeast life-span extension by calorie restriction is independent of NAD fluctuation. Science 302, 2124-2126.

Aparicio, O. M. \& Gottschling, D. E. (1994). Overcoming telomeric silencing: a trans-activator competes to establish gene expression in a cell cycle-dependent way. Genes Dev 8, 1133-1146.

Ashrafi, K., Lin, S. S., Manchester, J. K. \& Gordon, J. I. (2000). Sip2p and its partner snflp kinase affect aging in S. cerevisiae. Genes Dev 14, 1872-1885.

Bakker, B. M., Overkamp, K. M., van Maris, A. J. A., Kotter, P., Luttik, M. A. H., van Dijken, J. P. \& Pronk, J. T. (2001). Stoichiometry and compartmentation of NADH metabolism in Saccharomyces cerevisiae. FEMS Microbiol Rev 25, 15-37.

Bedalov, A., Gatbonton, T., Irvine, W. P., Gottschling, D. E. \& Simon, J. A. (2001). Identification of a small molecule inhibitor of Sir2p. Proc Natl Acad Sci U S A 98, 15113-15118.

Bitterman, K. J., Anderson, R. M., Cohen, H. Y., Latorre-Esteves, M. \& Sinclair, D. A. (2002). Inhibition of silencing and accelerated aging by nicotinamide, a putative negative regulator of yeast sir2 and human SIRT1. J Biol Chem 277, 45099-45107. 
Bitterman, K. J., Medvedik, O. \& Sinclair, D. A. (2003). Longevity regulation in Saccharomyces cerevisiae: linking metabolism, genome stability, and heterochromatin. Microbiol Mol Biol Rev 67, 376-399.

Bordone, L. \& Guarente, L. (2005). Calorie restriction, SIRT1 and metabolism: understanding longevity. Nat Rev Mol Cell Biol 6, 298-305.

Brown, G. C. \& Cooper, C. E. (editors) (1995). Bioenergetics, a Practical Approach. Oxford: IRL Press.

Brunet, A., Sweeney, L. B., Sturgill, J. F., Chua, K. F., Greer, P. L., Lin, Y., Tran, H., Ross, S. E., Mostoslavsky, R. \& other authors (2004). Stressdependent regulation of FOXO transcription factors by the SIRT1 deacetylase. Science 303, 2011-2015.

Cabiscol, E., Belli, G., Tamarit, J., Echave, P., Herrero, E. \& Ros, J. (2002). Mitochondrial Hsp60, resistance to oxidative stress, and the labile iron pool are closely connected in Saccharomyces cerevisiae. J Biol Chem 277, 44531-44538.

Delaunay, A., Isnard, A. D. \& Toledano, M. B. (2000). $\mathrm{H}_{2} \mathrm{O}_{2}$ sensing through oxidation of the Yap1 transcription factor. EMBO J 19, 5157-5166.

Fabrizio, P. \& Longo, V. D. (2003). The chronological life span of Saccharomyces cerevisiae. Aging Cell 2, 73-81.

Fabrizio, P., Pozza, F., Pletcher, S. D., Gendron, C. M. \& Longo, V. D. (2001). Regulation of longevity and stress resistance by Sch9 in yeast. Science 292, 288-290.

Fabrizio, P., Battistella, L., Vardavas, R., Gattazzo, C., Liou, L. L., Diaspro, A., Dossen, J. W., Gralla, E. B. \& Longo, V. D. (2004). Superoxide is a mediator of an altruistic aging program in Saccharomyces cerevisiae. J Cell Biol 166, 1055-1067.

Fabrizio, P., Gattazzo, C., Battistella, L., Wei, M., Cheng, C., McGrew, K. \& Longo, V. D. (2005). Sir2 blocks extreme life-span extension. Cell 123, 655-667.

Gallego, C., Gari, E., Colomina, N., Herrero, E. \& Aldea, M. (1997). The Cln 3 cyclin is down regulated by transcriptional repression and regulation during the $G_{1}$ arrest caused by nitrogen deprivation in budding yeast. EMBO J 16, 7196-7206.

Giannakou, M. E. \& Partridge, L. (2004). The interaction between FOXO and SIRT1: tipping the balance towards survival. Trends Cell Biol 14, 408-412.

Godon, C., Lagniel, G., Lee, J., Buhler, J. M., Kieffer, S., Perrot, M., Boucherie, H., Toledano, M. B. \& Labarre, J. (1998). The $\mathrm{H}_{2} \mathrm{O}_{2}$ stimulon in Saccharomyces cerevisiae. J Biol Chem 273, 22480-22489.

Gottschling, D. E., Aparicio, O. M., Billington, B. L. \& Zakian, V. A. (1990). Position effect at $S$. cerevisiae telomeres: reversible repression of Pol II transcription. Cell 63, 751-762.

Grubisha, O., Smith, B. C. \& Denu, J. M. (2005). Small molecule regulation of Sir2 protein deacetylases. FEBS J 272, 4607-4616.

Grune, T., Jung, T., Merker, K. \& Davies, K. J. (2004). Decreased proteolysis caused by protein aggregates, inclusion bodies, plaques, lipofuscin, ceroid, and 'aggresomes' during oxidative stress, aging, and disease. Int J Biochem Cell Biol 36, 2519-2530.

Harman, D. (1981). The aging process. Proc Natl Acad Sci U S A 78, 7124-7128.

Harris, N., Costa, V., MacLean, M., Mollapour, M., Moradas-Ferreira, P. \& Piper, P. W. (2003). Mnsod overexpression extends the yeast chronological $\left(\mathrm{G}_{0}\right)$ life span but acts independently of Sir2p histone deacetylase to shorten the replicative life span of dividing cells. Free Radic Biol Med 34, 1599-1606.

Harris, N., Bachler, M., Costa, V., Mollapour, M., Moradas-Ferreira, P. \& Piper, P. W. (2005). Overexpressed Sodlp acts either to reduce or to increase the lifespans and stress resistance of yeast, depending on whether it is $\mathrm{Cu}^{2+}$-deficient or an active $\mathrm{Cu}, \mathrm{Zn}$-superoxide dismutase. Aging Cell 4, 41-52.
Hasan, R., Leroy, C., Isnard, A. D., Labarre, J., Boy-Marcotte, E. \& Toledano, M. B. (2002). The control of the yeast $\mathrm{H}_{2} \mathrm{O}_{2}$ response by the Msn2/4 transcription factors. Mol Microbiol 45, 233-241.

Herman, P. K. (2002). Stationary phase in yeast. Curr Opin Microbiol 5, 602-607.

Jackson, M. D., Schmidt, M. T., Oppenheimer, N. J. \& Denu, J. M. (2003). Mechanism of nicotinamide inhibition and transglycosidation by Sir2 histone/protein deacetylases. J Biol Chem 278, 50985-50998.

Jakubowski, W., Bilinski, T. \& Bartosz, G. (2000). Oxidative stress during aging of stationary cultures of the yeast Saccharomyces cerevisiae. Free Radic Biol Med 28, 659-664.

Kaeberlein, M., McVey, M. \& Guarente, L. (1999). The SIR2/3/4 complex and SIR2 alone promote longevity in Saccharomyces cerevisiae by two different mechanisms. Genes Dev 13, 2570-2580.

Kaeberlein, M., Kirkland, K. T., Fields, S. \& Kennedy, B. K. (2004). Sir2-independent life span extension by calorie restriction in yeast. PLoS Biol 2, E296.

Kaiser, C., Michaelis, S. \& Michell, A. (editors) (1994). Methods in Yeast Genetics. Cold Spring Harbor, NY: Cold Spring Harbor Laboratory.

Kobayashi, Y., Furukawa-Hibi, Y., Chen, C., Horio, Y., Isobe, K., Ikeda, K. \& Motoyama, N. (2005). SIRT1 is critical regulator of FOXO-mediated transcription in response to oxidative stress. Int $J$ Mol Med 16, 237-243.

Kops, G. J., Dansen, T. B., Polderman, P. E., Saarloos, I., Wirtz, K. W., Coffer, P. J., Huang, T. T., Bos, J. L., Medema, R. H. \& Burgering, B. M. (2002). Forkhead transcription factor FOXO3a protects quiescent cells from oxidative stress. Nature 419, 316-321.

Krems, B., Charizanis, C. \& Entian, K. D. (1996). The response regulator-like protein Pos9/Skn7 of Saccharomyces cerevisiae is involved in oxidative stress resistance. Curr Genet 29, 327-334.

Kuge, S. \& Jones, N. (1994). YAP1 dependent activation of TRX2 is essential for the response of Saccharomyces cerevisiae to oxidative stress by hydroperoxides. EMBO J 13, 655-664.

Levine, R. L. (2002). Carbonyl modified proteins in cellular regulation, aging, and disease. Free Radic Biol Med 32, 790-796.

Lin, S. J. \& Guarente, L. (2003). Nicotinamide adenine dinucleotide, a metabolic regulator of transcription, longevity and disease. Curr Opin Cell Biol 15, 241-246.

Lin, S. J., Kaeberlein, M., Andalis, A. A., Sturtz, L. A., Defossez, P. A., Culotta, V. C., Fink, G. R. \& Guarente, L. (2002). Calorie restriction extends Saccharomyces cerevisiae life-span by increasing respiration. Nature 418, 344-348.

Lin, S. J., Ford, E., Haigis, M., Liszt, G. \& Guarente, L. (2004). Calorie restriction extends yeast life span by lowering the level of NADH. Genes Dev 18, 12-16.

Luk, E. E. \& Culotta, V. C. (2001). Manganese superoxide dismutase in Saccharomyces cerevisiae acquires its metal co-factor through a pathway involving the Nramp metal transporter, Smf2p. J Biol Chem 276, 47556-47562.

MacLean, M., Harris, N. \& Piper, P. W. (2001). Chronological lifespan of stationary phase yeast cells; a model for investigating the factors that might influence the ageing of postmitotic tissues in higher organisms. Yeast 18, 499-509.

Martinez-Pastor, M. T., Marchler, G., Schüller, C. S., Marchler-Bauer, A., Ruis, H. \& Estruch, F. (1996). The Saccharomyces cerevisiae zinc finger proteins Msn2p and Msn4p are required for transcriptional induction through the stress response element (STRE). EMBO J 15, 2227-2235.

Nemoto, S. \& Finkel, T. (2002). Redox regulation of forkhead proteins through a p66shc-dependent signaling pathway. Science 295, $2450-2452$. 
Nyström, T. (2005). Role of oxidative carbonylation in protein quality control and senescence. EMBO J 24, 1311-1317.

Piper, P. W. (1995). The heat shock and ethanol stress responses of yeast exhibit extensive similarity and functional overlap. FEMS Microbiol Lett 134, 121-127.

Reverter-Branchat, G., Cabiscol, E., Tamarit, J. \& Ros, J. (2004). Oxidative damage to specific proteins in replicative and chronological-aged Saccharomyces cerevisiae: common targets and prevention by calorie restriction. J Biol Chem 279, 31983-31989.

Rodriguez-Manzaneque, M. T., Ros, J., Cabiscol, E., Sorribas, A. \& Herrero, E. (1999). Grx5 glutaredoxin plays a central role in protection against protein oxidative damage in Saccharomyces cerevisiae. Mol Cell Biol 19, 8180-8190.

Schmitt, A. P. \& McEntee, K. (1996). Msn2p, a zinc finger DNAbinding protein, is the transcriptional activator of the multistress response in Saccharomyces cerevisiae. Proc Natl Acad Sci U S A 93, 5777-5782.

Sinclair, D. A. (2002). Paradigms and pitfalls of yeast longevity research. Mech Ageing Dev 123, 857-867.

Sinclair, D. A. \& Guarente, L. (1997). Extrachromosomal rDNA circles - a cause of aging in yeast. Cell 91, 1033-1042.

Smith, J. S. \& Boeke, J. D. (1997). An unusual form of transcriptional silencing in yeast ribosomal DNA. Genes Dev 11, 241-254.
Sohal, R. S. \& Weindruch, R. (1996). Oxidative stress, caloric restriction, and aging. Science 273, 59-63.

Stadtman, E. R. (1992). Protein oxidation and aging. Science 257, 1220-1224.

Stadtman, E. R. \& Levine, R. L. (2000). Protein oxidation. Ann N Y Acad Sci 899, 191-208.

Stadtman, E. R. \& Oliver, C. N. (1991). Metal-catalyzed oxidation of proteins. Physiological consequences. J Biol Chem 266, 2005-2008.

Tamarit, J., Irazusta, V., Moreno-Cermeño, A. \& Ros, J. (2006). Colorimetric assay for the quantitation of iron in yeast. Anal Biochem 351, 149-151.

Van der Horst, A., Tertoolen, L. G. J., Vries-Smits, L. M. M., Frye, R. A., Medema, R. H. \& Burgering, B. M. T. (2004). FOXO4 is acetylated upon peroxide stress and deacetylated by the longevity protein hSir2 ${ }^{\text {SIRT1 }}$. J Biol Chem 279, 28873-28879.

van Voorst, F. V., Houghton-Larsen, J., Jonson, L., Kielland-Brandt, M. C. \& Brandt, A. (2006). Genome-wide identification of genes required for growth of Saccharomyces cerevisiae under ethanol stress. Yeast 23, 351-359.

Williamson, V. M., Bennetzen, J., Young, E. T., Nasmyth, K. \& Hall, B. D. (1980). Isolation of the structural gene for alcohol dehydrogenase by genetic complementation in yeast. Nature 283, 214-216.

Edited by: M. Molina 